\title{
Enhancing English Phonemic Awareness of Thai Grade One Students through Multimedia Computer-assisted Language Learning
}

\author{
Niramol Thajakan \\ Department of English, Faculty of Humanities and Social Science, Lampang Rajabhat University, Lampang, Thailand \\ Usaporn Sucaromana \\ Department of Western Languages, Faculty of Humanities, Srinakharinwirot University, Bangkok, Thailand
}

\begin{abstract}
This study aims to investigate whether the English phonemic awareness of Thai grade one students can be enhanced through a multimedia CALL program while learning the English language through the whole word approach. It also explores Thai grade one students' views on improving phonemic awareness through a multimedia CALL program while learning the English language through the whole word approach. The research participants were 50 Thai grade one students who were classified into good, fair, and poor groups according to their English proficiency scores. The students in each group were divided equally into experimental and control groups: 25 students in the experimental group and 25 students in the control group. Then, three participants from each good, fair, and poor group were randomly selected to participate in a semistructured interview. Three phonemic awareness tests were used to collect quantitative data obtained from the experimental and control groups. These tests were analyzed using descriptive statistics (Mean and SD) and $t$ test. In addition, a semi-structured interview was used to collect qualitative data with the data being analyzed using content analysis. The results of the study revealed that the experimental group made significantly greater gains in English phonemic awareness than the control group at the $\mathbf{0 0 1}$ level. Moreover, the finding of the qualitative data indicated that the students who were provided with the multimedia CALL program had positive views on enhancing phonemic awareness through this supportive tool while learning the English language through the whole word approach.
\end{abstract}

Index Terms-phonemic awareness, CALL, multimedia, grade one students, English

\section{INTRODUCTION}

Phonemic awareness is a necessary early language literacy skill for the development of language skills in young learners (Fitzpatrick \& Yuh, 1997). Having a low level of phonemic awareness can result in language learning difficulties for many learners, especially in reading and spelling (Berg \& Stegelman, 2003). Previous studies (Anusornorakarn, 2002; Chinwonno, 2001; Mungsiri, 2002) have shown that many Thai EFL learners at all educational levels face many difficulties in learning a language and that one such problem is a lack of phonemic awareness. For example, many Thai learners who have weak phonemic awareness cannot distinguish between voiced and voiceless consonants in the English language (Pinnell \& Fountas, 2011).

Such awareness can be taught to learners of all levels and ages; however, it should be taught at an early agebetween three to eight because they can benefit the most (Center for the Improvement of Early Reading Achievement [CIERA], 2003; Zygouris-Coe, 2001). Teaching phonemic awareness to young learners can help them develop their language skills better than those who do not receive such education (Mehta, Foorman, Branum, \& Taylor, 2005; Strickland \& Riley-Ayers, 2006). The emphasis on teaching phonemic awareness is, thus, essential for the enhancement of Thai young learners' phonemic awareness in order to build the strong foundations for avoiding language learning difficulties.

Since Thai EFL learners learn English as a foreign language, teaching English phonemic awareness to them may cause them more difficulties in improving their phonemic awareness (Jannuzi, 1998). The major factor that causes difficulty is the differences between the English and Thai phonological systems (Lakhawatana, 1969). One study by Kanokpermpoon (2007) showed that the English sounds /g/, /v/, /z/, / $/ \theta /, / \delta /, / \mathrm{J} /, / 3 /, / \mathrm{d} / /, / \mathrm{t} /$, and $/ \mathrm{r} /$ are problematic for Thai EFL learners to recognize, distinguish and pronounce. Since these nine sounds do not exist in the Thai consonant system, Thai EFL learners have language learning difficulties in identifying and discriminating these sounds (Deterding \& Poedjosoedarmo, 1998; Thongsin, 2007; Tuaychareon, 2003). This results in Thai EFL learners being unaware of these nine problematic sounds and thus learning the language ineffectively. Consequently, the lack of awareness of some English consonant sounds among Thai EFL learners is one language learning problem that should be addressed (Sriprasidh, 2010). 
As for teaching the English language in Thailand, Thai EFL teachers employ various teaching techniques in the classroom which focus on developing the four major skills of Thai learners of English. These are often taught by the whole word approach (Darasawang, 2007; Dhanasobhon, 2006; Durongphan, Aksornkul, Sawangwong, \& Tiancharoen, 1982; Noom-ura, 2013; Wiriyachitra, 2002). According to Sriprasidh's study (2010), teaching the English language in Thailand normally starts from top to bottom, also known as the top-down approach, which begins with reading words by recognizing them by sights, that is, the whole word approach. Even though this approach requires learners to utilize whole word recognition skills to identify the spoken word and its meaning, it can also present the problem of a lack of phonemic awareness and result in language learning difficulties among many Thai learners. This shows that solely teaching with the whole word approach in the English classroom may not be enough.

A Multimedia Computer-Assisted Language Learning Program (CALL) is considered effective when used as a supportive tool to enhance young learners' phonemic awareness (French, 2004). Studies on enhancing young learners' phonemic awareness with multimedia CALL programs (Cassady \& Smith, 2003; Hecht \& Close, 2002; Hodgson \& Holland, 2010; Isakson, Marchand-Martella, \& Martella, 2011; Macaruso \& Walker, 2008; Mitchell \& Fox, 2001) have been conducted in many countries and have shown positive results. However, it is apparent that there have been no studies on developing the phonemic awareness of Thai EFL learners, especially young learners, through the use of a multimedia CALL program.

\section{METHODOLOGY}

This research was conducted as an embedded mixed method design to investigate the improvement of the English phonemic awareness of Thai grade one students through a multimedia CALL program while learning the English through the whole word approach. In addition, it aimed to reveal the Thai grade one students' views on practicing phonemic awareness through the multimedia CALL program while learning the English through the whole word approach.

\section{A. Sampling}

The sampling in this study was Thai grade one students, comprising both males and females. Out of 78 students, 50 students were selected to participate in this study by purposive sampling using English language capabilities. The researcher obtained the students' English proficiency scores from their teacher and used these scores to classify them into three groups; good, fair, and poor. A student who scored more than 75 out of 100 points was classified as being a student with good English. A student who scored between 65 to 74 points was classified as a student with fair English. A student who scored less than 65 out of 100 points was classified as a student with poor English. It was found that there were 16 students in the good English proficiency group, 24 students in the fair English proficiency group, and 10 students in the poor English proficiency group. Next, the researcher used simple random sampling to divide the students of each group into the experimental and control groups equally. Thus, there were 25 students in the experimental group and 25 students in the control group.

\section{B. Research Instruments}

Three instruments were used in this study: phonemic awareness tests, multimedia CALL program, and semistructured interview. A detailed description of the research instruments follows:

Phonemic awareness tests: phonemic awareness tests were used to measure Thai grade one students' performances in the phonemic awareness of English. In this study, the researcher constructed the tests by adapting two types of phonemic awareness test: Assessment and Instruction in Phonological Awareness 2002 (Florida Education, 2002) and Kirwan Assessment (Kirwan, 2002). The researcher constructed three phonemic awareness tests which were tracked by a pretest and posttest. These tests assessed three consonant pairs $/ \mathrm{k} /$ and /g/, /f/ and /v/, and /s/ and /z/. Each phonemic awareness test was divided into three levels of phonemic awareness: (a) phoneme isolation, (b) phoneme identity, and (c) phoneme categorization. Each test consisted of 15 items with 5 items for each level of phonemic awareness. There was a time limit of 20 minutes for each test.

Multimedia CALL program: the study developed a multimedia CALL program, Enjoy the Sounds!, which was an integrative CALL program that ran from a CD-ROM. It integrated phonemic awareness with multimedia-texts, sounds, animations, and pictures. The multimedia CALL program covered the problematic sounds in the English language that Thai EFL learners experience difficulties in recognizing and distinguishing, namely the three pairs of English consonants /k/ and /g/, /f/ and /v/, and /s/ and /z/. For each pair, there were three levels of phonemic awareness: (a) phoneme isolation, (b) phoneme identity, and (c) phoneme categorization. There were 20 items for each level of phonemic awareness. The participants were limited to 35 minutes of practice for each level of phonemic awareness. The multimedia CALL program was provided as a supportive tool for the participants with the aim of enhancing their English phonemic awareness.

Semi-structured interview: to elicit the Thai grade one students' views on utilizing the multimedia CALL program to improve phonemic awareness while learning the English through the whole word approach, three participants from the good, fair, and poor groups were randomly selected to take part in a semi-structured interview after finishing the last posttest. The questions in the interview were open-ended and designed to determine the students' views on improving 
phonemic awareness through the multimedia CALL program while learning the English language through the whole word approach. In order to avoid misunderstanding and to prevent miscommunication, the interview conducted in Thai which is the first language of the participants. During the interview, a tape recorder was used to record all the information supplied by the interviewed participants. Each interview took between 10 and 15 minutes. The questions of the semi-structured interview were:

1) Introduce yourself (name and nickname).

2) Do you enjoy learning with Enjoy the Sounds! program at the computer laboratory? Why or why not?

3) Do you enjoy learning English in the classroom? Why or why not?

4) Which one do you like the most - learning with the Enjoy the Sounds! program at the computer laboratory or learning English in the classroom? Why?

\section{Research Procedure}

The participants in both the experimental and control groups learned the English language in the classroom with the whole word approach through a Thai teacher. Besides learning English in the classroom, the participants in both groups were given additional activities. The experimental group was provided a multimedia CALL program to practice phonemic awareness at the computer laboratory, whereas the participants in the control group joined the fun English activities arranged by the school.

In the first period, the participants in both the experimental and control groups took the pretest to measure their English phonemic awareness of the English consonant pair $/ \mathrm{k} /$ and $/ \mathrm{g} /$. Afterwards, from the second to the fourth period, the experimental group practiced phonemic awareness of the pair / $/$ and /g/ through a multimedia CALL program, consisting of phoneme isolation, phoneme identity, and phoneme categorization. Additionally, they filled out worksheets after practicing phonemic awareness through a multimedia CALL program for each period. Next, in the fifth period, the researcher asked the experimental group to review three lessons of phonemic awareness of the pair / $\mathrm{k} /$ and /g/ through a multimedia CALL program and played game in the activity room. Then, in the sixth period, the participants in both the experimental and control groups completed the posttest of English phonemic awareness in consonant pair $/ \mathrm{k} /$ and $/ \mathrm{g} /$ and took the pretest of English phonemic awareness of pair /f/ and /v/. From the seventh through the sixteenth period, students in the experimental group repeated activities in the English consonant pairs /f/ and $/ \mathrm{v} /$, and /s/ and /z/. Additionally, in the eighteenth period, nine participants, consisting of three participants from each of the good, fair, and poor groups, were randomly selected to join a semi-structured interview.

As regards taking each phonemic awareness test, participants in both the experimental and control groups were limited to 20 minutes. Moreover, practicing phonemic awareness with a multimedia CALL program took 60 minutes for each period and one assistant attended the computer laboratory with the participants in the experimental group in order to help them when they had questions or problems while practicing. The assistant was an American teacher who taught English at primary level - grades one to six. Furthermore, the interview section took between 5 to 10 minutes each person.

\section{Data Analysis}

Quantitative data analysis: a quantitative statistical analysis was conducted using the data obtained from the phonemic awareness tests. The data was analyzed using descriptive statistics (mean and standard deviation). The $t$-test was used to discover whether there were significant differences within the experimental group and the control group; moreover, between the experimental group and the control groups in terms of the scores gained from the pretests and posttests.

Qualitative data analysis: a qualitative data analysis was conducted with the data obtained from the semi-structured interview. All the information from the interviewed was analyzed using content analysis; thus, the data was classified into positive or negative views.

\section{FINDINGS AND DISCUSSION}

\section{A. Quantitative Findings}

Results of phonemic awareness tests of the experimental group and the control group: the results of the quantitative data showed that the students in the experimental group who were supported by a multimedia CALL program in combination with the use of the whole word approach could improve their English phonemic awareness. The students in the experimental group obtained higher scores on three posttests of phonemic awareness tests compared to the pretests. This revealed that phonemic awareness appears to be improved by a supportive tool, such as a multimedia CALL program. 
TABLE I

COMPARISON BETWEEN THE PRETESTS AND POSTTESTS OF PHONEMIC AWARENESS TESTS FOR /K/ AND/G/,/F/ AND/V/, AND/S/ AND/Z/ OF THE EXPERIMENTAL GROUP AND THE CONTROL GROUP

\begin{tabular}{|c|c|c|c|c|c|c|c|}
\hline \multirow{2}{*}{ Variable } & \multirow{2}{*}{ Group } & \multicolumn{2}{|c|}{ Pretest } & \multicolumn{2}{|c|}{ Posttest } & \multirow[b]{2}{*}{$\mathrm{t}$} & \multirow[b]{2}{*}{$p$} \\
\hline & & $\mathrm{M}$ & SD & $\mathrm{M}$ & SD & & \\
\hline \multirow{2}{*}{$/ \mathrm{k} /$ and $/ \mathrm{g} /$} & Experimental & 5.72 & 1.14 & 11.20 & 1.35 & 26.20 & .000 \\
\hline & Control & 5.64 & 1.08 & 5.76 & 1.13 & .50 & .622 \\
\hline \multirow{2}{*}{ /f/ and /v/ } & Experimental & 5.84 & .90 & 10.68 & 1.63 & 18.90 & .000 \\
\hline & Control & 5.80 & 1.26 & 5.36 & 1.41 & -2.68 & .013 \\
\hline \multirow{2}{*}{ /s/ and /z/ } & Experimental & 5.64 & .91 & 10.64 & 1.50 & 16.37 & .000 \\
\hline & Control & 5.68 & 1.18 & 5.60 & 1.35 & -.70 & .491 \\
\hline
\end{tabular}

According to Table I, for the phonemic awareness test of $/ \mathrm{k} /$ and $/ \mathrm{g} /$, the posttest score of the experimental group was higher than the pretest score at the .001 significance level. Conversely, the posttest score of the control group was only slightly higher than the pretest score. That is, there were no significant differences in the posttest scores of the control group.

With regard to the score from the phonemic awareness test of /f/ and /v/, the posttest score of the experimental group was higher than the pretest at the .001 level of significance. The posttest score of the control group was lower than the pretest.

Likewise, for the phonemic awareness test of $/ \mathrm{s} /$ and $/ \mathrm{z} /$, the posttest score increased, compared to the pretest at the .001 significance level. Meanwhile, the posttest score of the control group decreased slightly, compared to the pretest.

The results of the present research were consistent with studies of researchers in the fields of phonemic awareness and CALL programs. The first study was Mitchell and Fox (2001), in which there were higher gains after practicing phonemic awareness with multimedia programs. The researcher investigated the effect of multimedia computer programs on increasing American children's phonemic and phonological awareness. Their results showed that 36 kindergarten and 36 first grade students improved their phonemic and phonological awareness. This demonstrates that a multimedia CALL program is effective as a supportive tool for building phonemic awareness. It can be applied to assist not only young learners, but also children with a poor standard of English.

Additionally, the results of the present study were also in accordance with the research of Hodgson and Holland (2010), in which students obtained better scores after training through multimedia programs. Their study examined the effectiveness of interactive multimedia programs on the phonemic and phonological skills of at-risk American students in elementary school. The results revealed that 68 students who participated in their study gained higher scores for the whole group from the pretest to posttest. Consequently, this illustrates that students in general and special education programs can develop their phonemic awareness with an effective tool such a multimedia CALL program.

Moreover, the results of the current study were also consistent with the study of Isakson, Marchand-Martella, and Martella (2011), in which phonemic awareness was improved through a phonemic awareness program. The researchers explored the effect of a phonemic awareness program in helping preschool children with developmental delays to develop their phonemic awareness. The results showed that the phonemic awareness of all five children with developmental delays were enhanced. The findings of the present study and the study of Isakson, Marchand-Martella, and Martella (2011), both demonstrate that the phonemic awareness of general students or children with developmental delays can be enhanced with an effective tool, such as a multimedia CALL program.

TABLE II.

ANALYSIS OF THE COVARIANCE OF PHONEMIC AWARENESS TESTS FOR

/K/ AND /G/, /F/ AND/V/, AND/S/ AND / / / BETWEEN THE EXPERIMENTAL AND THE CONTROL GROUPS

\begin{tabular}{|l|l|l|l|l|l|l|}
\hline Variable & Source of Variance & $\mathrm{df}$ & $\mathrm{SS}$ & $\mathrm{MS}$ & $\mathrm{F}$ & $p$-Value \\
\hline$/ \mathrm{k} /$ and /g/ & Pretest & 1 & 22.34 & 22.34 & 20.10 & .000 \\
& Group & 1 & 362.75 & 362.75 & 326.46 & .000 \\
& Error & 47 & 52.22 & 1.11 & & \\
\cline { 2 - 7 } & Total & 50 & 4040.00 & & & \\
\hline /f/ and /v/ & Pretest & 1 & 55.69 & 55.69 & 47.16 & .000 \\
& Group & 1 & 348.44 & 348.44 & 295.03 & .000 \\
& Error & 47 & 55.51 & 1.18 & & \\
\cline { 2 - 7 } & Total & 50 & 3681.00 & & & \\
& Pretest & 1 & 35.67 & 35.67 & 27.00 & .000 \\
& Group & 1 & 321.54 & 321.54 & 243.38 & .000 \\
& Error & 47 & 62.09 & 1.32 & & \\
\cline { 2 - 7 } & Total & 50 & 3712.00 & & & \\
\hline
\end{tabular}

Results of phonemic awareness tests between the experimental and the control groups: In terms of the results of phonemic awareness tests between the experimental and the control groups, the experimental group made significantly greater gains in English phonemic awareness than the control group.

According to Table II, there were significant differences in the scores regarding three phonemic awareness tests for $(/ \mathrm{k} /$ and $/ \mathrm{g} /)$, (/f/ and $/ \mathrm{v} /)$, and $(/ \mathrm{s} /$ and $/ \mathrm{z} /)$ between the experimental and control groups stood at the .001 level of significance. Additionally, the posttest score was higher than the pretest score, with the statistically significant 
difference at .001 . It shows that the students in the experimental group got higher scores in the three posttests than the students in the control group. As a result, phonemic awareness can be enhanced through a multimedia CALL program.

The results were in accordance with three research studies, in which there were greater gains after training with multimedia program. Firstly, the findings were relevant to the research of Hecht and Close (2002). Forty-two kindergarten students were assigned to learn with phonemic awareness software; however, another 34 students received no training. The study revealed that the students in the treatment group had better scores on the posttest than the students in the control group.

Secondly, the findings of the present study were also consistent with Cassady and Smith (2003). The researchers assigned the kindergarteners in the experimental group practice of phonemic and phonological awareness with a computer program while the control group did not receive any supplement. Subsequently, the results revealed that the experimental group developed and performed better at phonemic awareness than the control group. Lastly, the outcome of the present study was also in accordance with the study of Macaruso and Walker (2008). Forty-seven elementary school students in the experimental group were trained with a computer program as another 47 students in the control group undertook language arts activities in a regular classroom. After training, the experimental group improved more in the posttest scores than the control group. In the current study, the results are similar to the three studies mentioned earlier because the students who received a multimedia CALL program improved more in English phonemic awareness than the students who did not. Hence, it can be seen that a multimedia CALL program is effective to use as a supportive material in assisting young children to enhance their phonemic awareness of English.

\section{B. Qualitative Findings}

Nine participants, comprising three participants from each of the good, fair, and poor groups, were randomly selected to be interviewed in this study on their views on improving phonemic awareness through a multimedia CALL program while learning the English language through the whole word approach. The findings from the semi-structured interview are presented as follows:

When the three participants from each of the good, fair, and poor groups were asked "Do you enjoy learning through the Enjoy the Sounds! program at the computer laboratory? Why or why not?", all participants answered "Yes". This indicated that they all enjoyed practicing phonemic awareness through the multimedia CALL program while learning the English language through the whole word approach. Below are the responses they gave in support of their answers:

"I enjoy learning through the multimedia CALL program because I feel like I am playing a game and the program also contains many fun songs." (Students $A$ and $H$ )

Additionally, nine participants also were asked "Do you enjoy learning English in the classroom? Why or why not?". Six participants enjoyed it and their responses are shown below:

"Yes. Teacher gives me and my friends many activities to do such as singing, dancing, and painting." (Students A and $D)$

However, three participants expressed some negative views towards learning English in the classroom. For example:

"No, I do not enjoy it because sometimes I cannot answer questions teacher asks me and my classmates laugh at me." (Student E)

On the other hand, nine participants were asked the question "Which one do you like the most - learning through the Enjoy the Sounds! program at the computer laboratory or learning English in the classroom? Why?" All participants chose learning with the Enjoy the Sounds! program at the computer laboratory since they could learn by themselves and it was more attractive. All of the responses are shown below:

"I like learning with the Enjoy the Sounds! program because I can practice lessons by myself." (Students A, $C$ and $H$ )

From these results, it can be concluded that Thai grade one students had positive views on enhancing phonemic awareness through the multimedia CALL program. They were both motivated by and interested in the program. The results are consistent with the research of Hecht and Close (2002), in which students who learned through a multimedia program enjoyed this style of learning. The researcher interviewed kindergarten students who had been given activities through multimedia computer software in order to investigate their attitude towards developing phonemic awareness with multimedia computer software after training for six months. The findings of the study showed that they all had positive attitudes towards practicing their phonemic awareness through this material. The results of the study and the study of Hecht and Close (2002) demonstrate that kindergarten students enjoy practicing phonemic awareness through this instructional material; additionally, this material can motivate students to learn English.

The findings of the current study are also in accordance with the study of Hodgson and Holland (2010), in which students enjoyed and were motivated in learning with multimedia program. Forty students of elementary school were interviewed to explore their opinions on learning phonemic and phonological skills with the interactive multimedia program. The results showed that all 40 students enjoyed and were interested in practicing phonemic and phonological skills with the interactive multimedia program. These two studies draw similar conclusions which show that the participants enjoyed practicing phonemic awareness through this material.

\section{CONCLUSION}


In conclusion, English phonemic awareness of Thai grade one students can be enhanced by the use of a multimedia CALL program in combination with the use of the whole word approach. Furthermore, all students provided a multimedia CALL program had positive views towards improving phonemic awareness through the multimedia CALL program while learning the English language through the whole word approach. This seems to indicate that a multimedia CALL program is effective as a supportive tool for building phonemic awareness. A multimedia CALL program can also increase students' interest and motivation because it can be created with a variety of activities that can encourage students to practice phonemic awareness (Nurulumama, 2010). Moreover, it can produce a positive language learning environment because students find the program enjoyable and thus it encourages them to learn the language (Gunduz, 2005).

\section{RECOMMENDATIONS FOR FURTHER STUDY}

Firstly, there are many problematic consonant pairs of English that Thai EFL learners find difficulty in perceiving, discriminating, and pronouncing. Consequently, more research should create a multimedia CALL program or other materials to improve other problematic consonant pairs - not only the three pairs of $/ \mathrm{k} / \mathrm{and} / \mathrm{g} /, \mathrm{f} /$ and $/ \mathrm{v} /$, and /s/ and /z/

Secondly, due to the fact that the Center for the Improvement of Early Reading Achievement [CIERA] (2003) has classified phonemic awareness into eight levels, the researcher of this study chose only three levels of phonemic awareness. The researcher suggests that further study should enhance more complex phonemic awareness levels of Thai EFL learners.

Thirdly, this study was conducted with grade one students. It is recommended that further studies should be conducted with other grade levels of students or other groups of students in different contexts.

Lastly, this study used semi-structured interviews as one of the research instruments to obtain the views of nine students towards developing phonemic awareness through a multimedia CALL program while learning the English language through the whole word approach. It is suggested that further study should be conducted with a greater sample size which may help to gain more credible and detailed information regarding grade one students' views.

\section{ACKNOWLEDGMENT}

I would like to express my utmost appreciation to my research advisor for her care, enthusiasm, and the value advice she provided me throughout this research. Finally, I am deeply grateful to my parents, family, and beloved for their love, support, and belief in me.

\section{REFERENCES}

[1] Anusornorakarn, W. (2002). Problems in reading comprehension (Master thesis). Yala Rajabhat University, Yala, Thailand.

[2] Berg, M., \& Stegelman, T. (2003). The critical role of phonological and phonemic awareness in reading success: A model for early literacy in rural schools. Rural Special Education Quarterly, 22(4), 47-54.

[3] Cassady, J. C., \& Smith, L. L. (2003). The impact of a reading-focused integrated learning system on phonological awareness in kindergarten. Journal of Literacy Research, 35(4), 947-964.

[4] Center for the Improvement of Early Reading Achievement [CIERA]. (2003). Put reading first: The research building blocks for teaching children to read. Washington, DC: U.S. Government Printing Office.

[5] Chinwonno, A. (2001). A comparison of Thai and English reading comprehension strategies of pre-service teachers in Thailand (Doctoral dissertation). Ohio University, Ohio, United States.

[6] Darasawang, P. (2007) English language teaching and education in Thailand: A decade of change. In D. Prescott (Ed.), English in Southeast Asia: Varieties, Literacies and Literatures Newcastle (pp. 187-204). Cambridge, United Kingdom: Cambridge Scholars Publishing.

[7] Deterding, D. H., \& Poedjosoedarmo, G. R. (1998). The sounds of English: Phonetics and phonology for English teachers in Southeast Asia. Singapore: Prentice Hall.

[8] Dhanasobhon, S. (2006). English language teaching dilemma in Thailand. Retrieved from http://www.curriculumandinstruction.org/index.php?lay=show\&ac=article \&Id=539134523\&Ntype $=7$.

[9] Durongphan, M., Aksornkul, N., Sawangwong, W., \& Tiancharoen, S. (1982). The development of English teaching in Thailand: A Rattanakosin Experience. Bangkok, Thailand: Aksorn Charoentat Publishing Company.

[10] Fitzpatrick, J., \& Yuh, C. (1997). Phonemic awareness: Playing with sounds to strengthen beginning reading skills. Cypress, CA: Creative Teaching Press.

[11] Florida Education. (2002). Assessment and instruction in phonological awareness 2002. Retrieved from http://www.paec.org/itrk3/files/pdfs/readingpdfs/cooltoolsphonological.pdf.

[12] French, L. (2004). Computers and developing phonemic awareness. Early Childhood Research Quarterly, 1(1), 138-149.

[13] Gunduz, N. (2005). Computer assisted language learning. Journal of Language and Linguistic Studies, 1(2), $193-214$.

[14] Hecht, S.A., \& Close, L. (2002). Emergent literacy skills and training time uniquely predict variability in responses to phonemic awareness training in disadvantaged kindergarteners. Journal of Experimental Child Psychology, 82(2), 93-115.

[15] Hodgson, A. B., \& Holland, N. E. (2010). Webber HearBuilder phonological awareness efficacy study: Improved phonological awareness skills for at-risk students. Greenville, SC: Super Duper Publication.

[16] Isakson, L., Marchand-Martella, N., \& Martella, R. C. (2011). Assessing the effects of the McGraw Hill Phonemic Awareness program with preschool children with developmental delays: A case study. Education and Treatment of Children, 34, 373-388.

[17] Jannuzi, C. (1998). Key concepts in EFL literacy: Phonemic awareness. Literacy across Cultures, 3(1), 7-12. 
[18] Kanokpermpoon, M. (2007). Thai and English consonantal sounds: A problem or a potential for EFL learning? ABAC Journal, 27(1), 57-66.

[19] Kirwan, C. (2002). Kirwan assessment. Chicago, IL: Longview.

[20] Lakhawatana, P. (1969). A constructive study of English and Thai. Bangkok, Thailand: The English Language Center.

[21] Macaruso, P., \& Walker, A. (2008). The efficacy of computer-assisted instruction for advancing literacy skills in kindergarten children. Reading Psychology, 29, 266-287.

[22] Mehta, P., Foorman, B. R., Branum, M. L., \& Taylor, P. W. (2005). Literacy as a unidimensional construct: Validation, sources of influence, and implications in a longitudinal study in grades 1 to 4. Scientific Studies of Reading, 9(2), 85-116.

[23] Mitchell, M. J., \& Fox, B. J. (2001). The effects of computer software for developing phonological awareness in low-progress readers. Reading Research \& Instruction, 40(4), 315-322.

[24] Mungsiri, P. (2002). Strategies for reading: Instructional materials for first year farm mechanic students at Rajamangala Institute of Technology, Southern Campus, Songkla (Unpublished Minor Thesis). Prince of Songkla University, Songkhla. Thailand.

[25] Noom-ura, S. (2013). English teaching problems in Thailand and Thai teachers' professional development needs. English Language Teaching, 6(11), 139-147.

$\begin{array}{lllll}\text { [26] Nurulumama. } & \text { (2010). language learning. } & \text { Retrieved from }\end{array}$ http://nurulumama.wordpress.com/2010/11/11/200/.

[27] Pinnell, G. S., \& Fountas, I. C. (2011). Literacy beginnings: A prekindergarten handbook. Portsmouth, NH: Heinemann.

[28] Sriprasidh, I. (2010). The research building blocks for teaching children how to read by national institute for literacy. AsiaPacific Programme of Educational Innovation for Development. Retrieve from http://www.oknation.net/blog/englishclinic/2009/06/24/entry-3.

[29] Strickland, D., \& Riley-Ayers, S. (2006). Early literacy: Policy and practice in the preschool years. New Brunswick, NJ: National Institute for Early Education Research.

[30] Thongsin, N. (2007). A study of English pronunciation problems for Thai learners (Unpublished master's independent study). Naresuan University, Phitsanulok, Thailand.

[31] Tuaychareon, P. (2003). A reflection of Thai English. Journal of Language and Linguistics, 21(2), 47-65.

[32] Wiriyachitra, A. (2002). English-language teaching and learning in Thailand in this decade. Thai TESOL Focus, 15(1), 4-9.

[33] Zygouris-Coe, V. (2001). Phonemic Awareness. Orlando, FL: Florida Literacy and Reading Excellence Center.

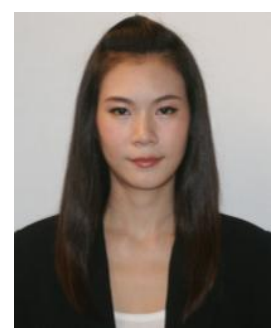

Niramol Thajakan was born in Phayao, Thailand in 1987. She holds a Bachelor degree in English from Mae Fah Luang University, Chiang Rai, Thailand in 2010, and Master degree in English from Srinakharinwirot University, Bangkok, Thailand in 2014. She presented her paper at International Conference on Linguistics, Literature and Arts-ICLLA2014. Her current research interests are applied linguistics, second language acquisition, and foreign language teaching.

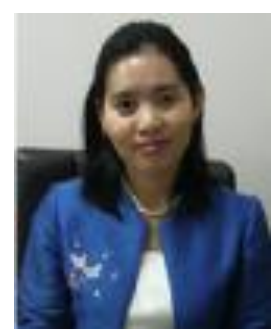

Usaporn Sucaromana (Ph.D.) is an assistant professor at Srinakharinwirot University in the Department of Western Languages, Faculty of Humanities. Her interests include applied linguistics, foreign language teaching, language testing and psycholinguistics. 